Canadian

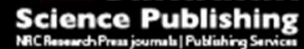

Canadian Journal of Chemistry Revue canadienne de chimie

\title{
Mass spectrometric characterization of oligomeric phosphaalkenes
}

\begin{tabular}{|r|l|}
\hline Journal: & Canadian Journal of Chemistry \\
\hline Manuscript ID & cjc-2016-0206.R1 \\
\hline Danuscript Type: & Article \\
\hline Complete List of Authors: & $\begin{array}{l}\text { Gillon, Bronwyn; University of British Columbia } \\
\text { Gates, Derek; University of British Columbia } \\
\text { Henderson, Matthew; Department of Chemistry } \\
\text { Janusson, Eric; Department of Chemistry } \\
\text { McIndoe, J. Scott; Department of Chemistry }\end{array}$ \\
\hline Keyword: & $\begin{array}{l}\text { mass spectrometry, phosphorus, polymer, electrospray ionization, } \\
\text { oligomers }\end{array}$ \\
\hline
\end{tabular}

SCHOLARONE $^{\text {m }}$

Manuscripts 
Bronwyn H. Gillon and Derek P. Gates*

\section{Matthew A. Henderson, Eric Janusson and J. Scott McIndoe*}

Department of Chemistry, University of Victoria, P.O. Box 3065, Victoria, BC V8W3V6, Canada. Email: mcindoe@uvic.ca; Fax: +1 (250) 721-7147; Tel: +1 (250) 721-7181.

12 In honour of Reg Mitchell, scientist and bon vivant.

\section{Keywords}




\section{Abstract}

20 Oligomeric phosphalkenes are readily characterized using electrospray ionization mass spectrometry

21 (ESI-MS). The high affinity of phosphines for silver ions permits the detection of the unadulterated

22 polymer as $[\mathrm{M}+x \mathrm{Ag}]^{x+}$ ions $(x=2-3)$. When the oligomers are oxidized using $\mathrm{H}_{2} \mathrm{O}_{2}$, the resulting

23 phosphine oxide polymer may be treated with sodium ions to produce $[\mathrm{M}+x \mathrm{Na}]^{x+}$ ions $(x=2-3)$. Both

24 methods predict a similar distribution of oligomers: $M_{n}$ values of $3450 \pm 100$ Da and a PDI of $1.09 \pm 0.01$

25 cover both analyses. This distribution represents oligomers of the general formula $\mathrm{Me}\left(\mathrm{PMesCPh}_{2}\right)_{n} \mathrm{H}$

26 from $n=4-20$ and maximizing at $\sim n=10$.

27

28 


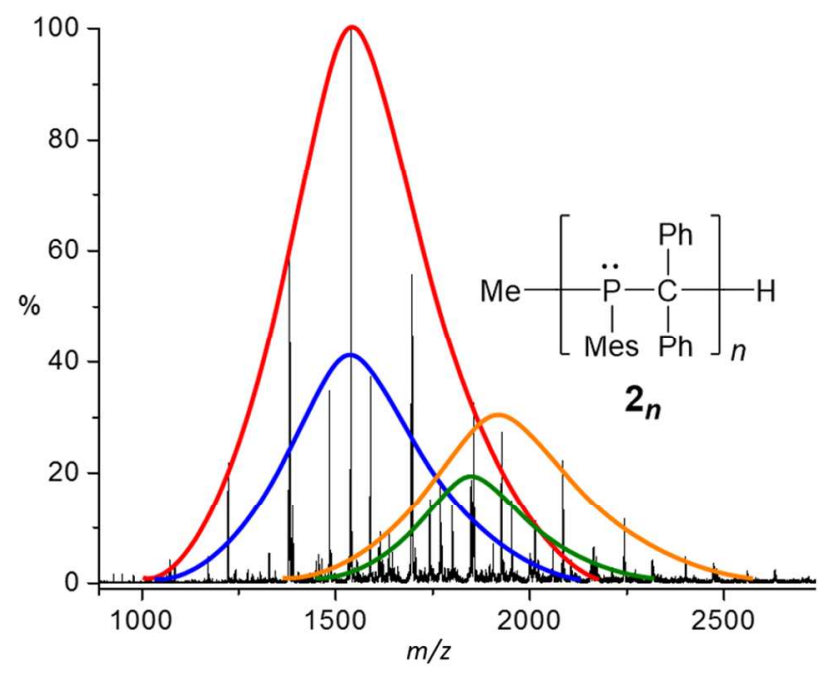

32 


\section{Introduction}

The development of phosphorus-containing polymers is motivated by the prospect of discovering new materials with unique properties, structures and chemical functionality ${ }^{1-5}$. Despite the widespread importance of polyphosphazenes ${ }^{6,7}$, developments in phosphorus polymer chemistry is hindered by the lack of general synthetic methods to incorporate phosphorus atoms into long chains. Recently, there have been numerous advances in the synthesis of phosphorus macromolecules ${ }^{8}$.

The addition polymerization of olefins is perhaps the most widely applicable and general method of organic polymer synthesis. By contrast, the polymerization of heavier-element-containing multiple bonds remains largely unexplored, even being dismissed for heavy element multiple bonds (e.g. $\mathrm{Si}=\mathrm{Si}){ }^{9}$. Over the past decade, our group and the group of Baines have successfully developed a polymerization chemistry for the $\mathrm{P}=\mathrm{C}$ bonds ${ }^{4}$, and $\mathrm{Si}=\mathrm{C}$ or $\mathrm{Ge}=\mathrm{C}$ bonds ${ }^{10,11}$. For phosphaalkenes, we have developed routes to homo- and co-polymers using radical and living anionic methods of polymerization and have shown that the resultant poly(methylenephosphine)s have unique properties and potential applications as: supports for metal-catalyzed organic transformations, flame retardants, templates for the self-assembly of gold nanostructures, and turn-on sensor materials ${ }^{12-23}$. Recent work has shown that the radical polymerization of $\mathbf{1}$ proceeds via an unprecedented addition-isomerization mechanism whereby the $o$-Me group of Mes is activated and serves as the propagating species (see: 2 where $\mathrm{x}>>\mathrm{y})^{24}$. Although still under investigation, we believe that the anionic polymerization of PMes phosphaalkenes may follow a similar pathway.

Although these recent mechanistic investigations involved multinuclear one- and twodimensional NMR spectroscopy, we earlier studied the MALDI-TOF MS of oligomers derived from the anionic oligomerization of $\mathrm{MesP}=\mathrm{CPh}_{2}$ with $\mathrm{MeLi}$ or BuLi (25 mol\%) ${ }^{25}$. Oligomerization of 1 (Scheme 1) leads to a mixture of oligomeric species $\left(\mathbf{2}_{\boldsymbol{n}}\right)$ that can be characterized by MALDI-TOF MS as the phosphine oxides $\left(\mathbf{3}_{\boldsymbol{n}}\right)$ after oxidation with $\mathrm{H}_{2} \mathrm{O}_{2}$. These results revealed oligomers stretching out 
59 to $\sim 3500 \mathrm{Da}$, with an exponential decay in intensity beyond the trimer. The oligomers were of two 60 types: the expected oligomeric series $\left[3_{n}+\mathrm{H}\right]^{+}$, and an additional series $\left[\mathbf{4}_{n}+\mathrm{H}\right]^{+}$, which appeared as 61 though it might arise either through fragmentation during the ionization process or via genuine 62 chemistry during polymerization. MALDI-TOF has been used previously to characterize phosphorus63 containing dendrimers up to generation 4 , with a variety of fragmentation processes observed ${ }^{26}$. 64 Oligomers with phosphonium end-groups have been characterized by both MALDI and ESI-MS ${ }^{27}$. The use of ESI-MS to characterize inorganic polymers has been fairly limited. Poly(aminoboranes) have been shown to be detectable by ESI-MS up to $n=49^{28}$; we are not aware of any previous studies characterizing poly(methylenephosphine)s by ESI-MS.
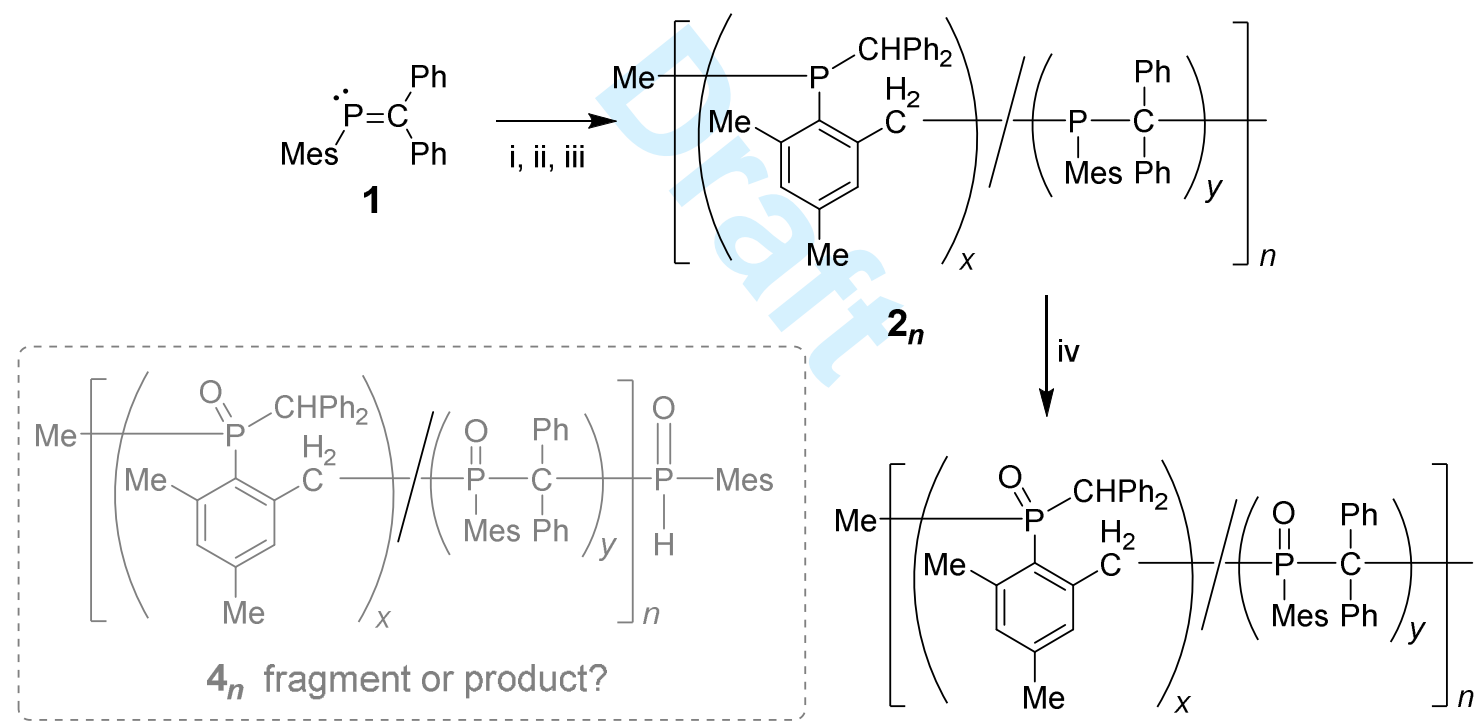

$3_{n}$ 
Results and Discussion Herein, we describe the analysis of oligomeric models for polymer $\mathbf{2}$ by using ESI-MS methods

$7 \mathbf{2}^{29}$, both with and without oxidation of the oligomeric products. The oligomers, $\mathbf{2}_{\mathbf{n}}$, were prepared 79 following the identical procedure to that described previously for the earlier MALDI-TOF analyses 80 (Scheme 1) ${ }^{25}$. ESI-MS is a powerful tool for the examination of inorganic materials ${ }^{30,31}$. ESI-MS 81 relies on being able to analyze ions, so examining neutral compounds such as those under study 82 requires the addition of a cation, whose identity is best selected based on the affinity of the neutral 83 compound for different cations. Before oxidation, the mixture of oligomers $\mathbf{2}_{\boldsymbol{n}}$ has phosphorus sites in 84 the backbone with a free lone pair that has high affinity for soft metal ions such as silver. So the initial 85 analysis involved adding a drop of $\mathrm{AgNO}_{3}$ solution to an acetonitrile solution of the oligomer mixture 8632,33 . The resulting mass spectrum was complicated but entirely tractable to assignment, as $\sim 99 \%$ of the 87 total ion current could be attributed to reasonable species that had acquired charge through 88 cationization (Figure 1). 
90

91

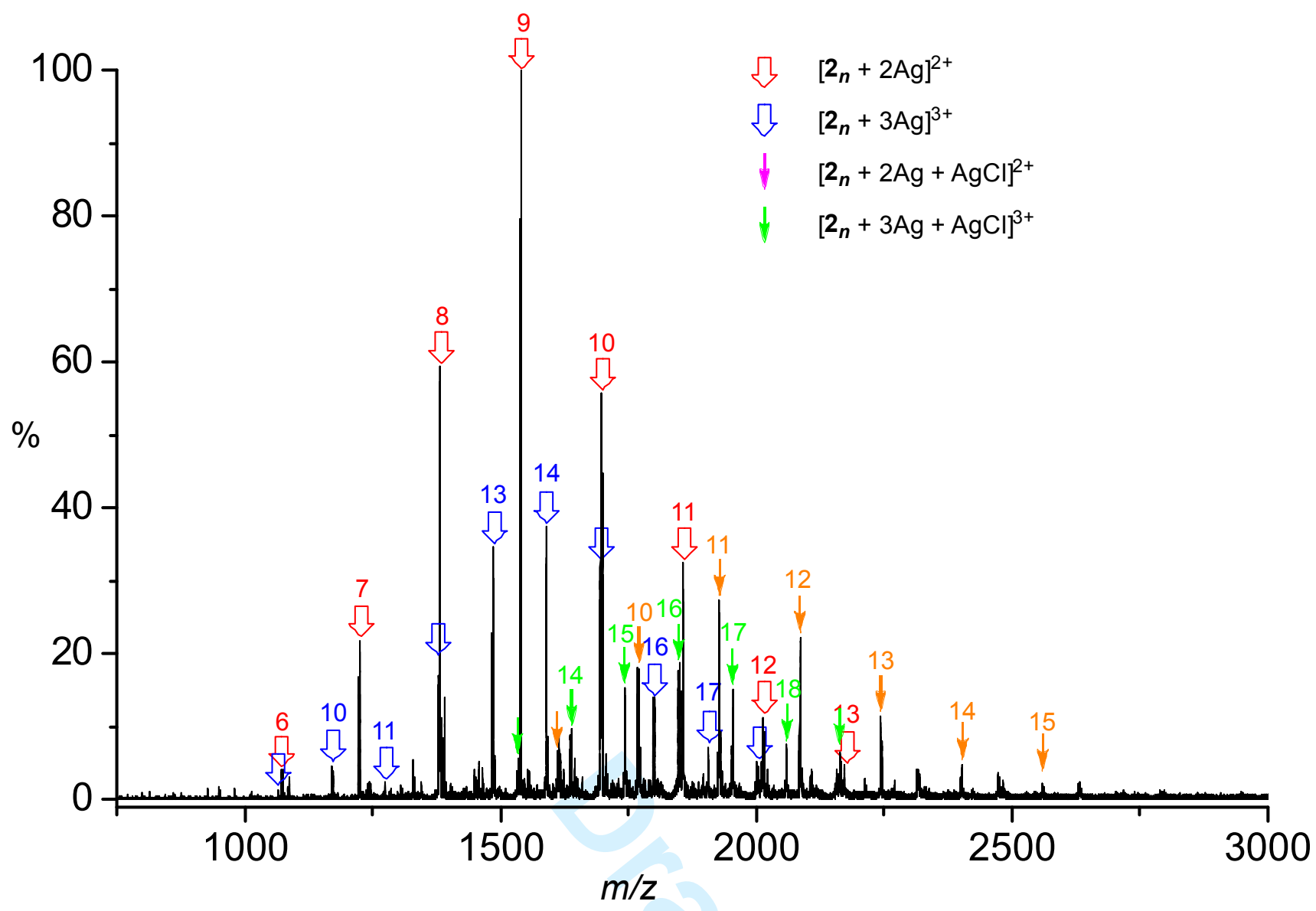

Figure 1. Positive ion ESI-MS of oligomerized phosphaalkene 1 to make oligomeric mixture $\mathbf{2}_{\boldsymbol{n}}$, recorded in acetonitrile with the addition of $\mathrm{AgNO}_{3}$.

None of the species observed were monocations. All of the oligomers were bound to at least two silver ions. The most prominent series consisted of the dications $\left[\mathbf{2}_{\boldsymbol{n}}+2 \mathrm{Ag}\right]^{2+}$, which provided a distribution between $n=6$ and $n=13$, with $n=9$ being most abundant. The fact that the peaks in the isotope pattern are $m / z \quad 0.5$ apart readily identifies the dicationic nature of these species. The next highest series was $\left[\mathbf{2}_{n}\right.$ $+3 \mathrm{Ag}]^{3+}$, appearing between $n=9$ and $n=18$, and peaking at $n=14$ (all have peaks in the isotope pattern $\mathrm{m} / \mathrm{z} 0.33$ apart). Unsurprisingly, the more phosphorus in an oligomer, the more likely it is to associate with more silver ions. Two smaller series also appear as a manifestation of the high affinity of silver ions for chloride ions, the di- and tricationic species $\left[\mathbf{2}_{n}+3 \mathrm{Ag}+\mathrm{Cl}\right]^{2+}(n=9-15)$ and $\left[\mathbf{2}_{n}+4 \mathrm{Ag}\right.$ 
$103+\mathrm{Cl}]^{3+}(n=13-19)$. While chloride was not directly involved in the analysis at any point, it is one of

104 those ions that is almost impossible to exclude from the instrument entirely, and the oligomers had

105 been in contact with $\mathrm{CH}_{2} \mathrm{Cl}_{2}$.

106

107 Making the approximation that the area of each peak is proportional to the abundance of that species,

108 we can sum the contributions of each mass spectrometrically observed series to the overall distribution

109 (Figure 2). No oligomers below $n=4$ or above $n=20$ were observed, and the distribution maximises at $110 n=9$. The $M_{\mathrm{n}}$ and $M_{\mathrm{w}}$ were calculated at 3550 and $3800 \mathrm{Da}$, respectively, giving a polydispersity index 111 of 1.07.

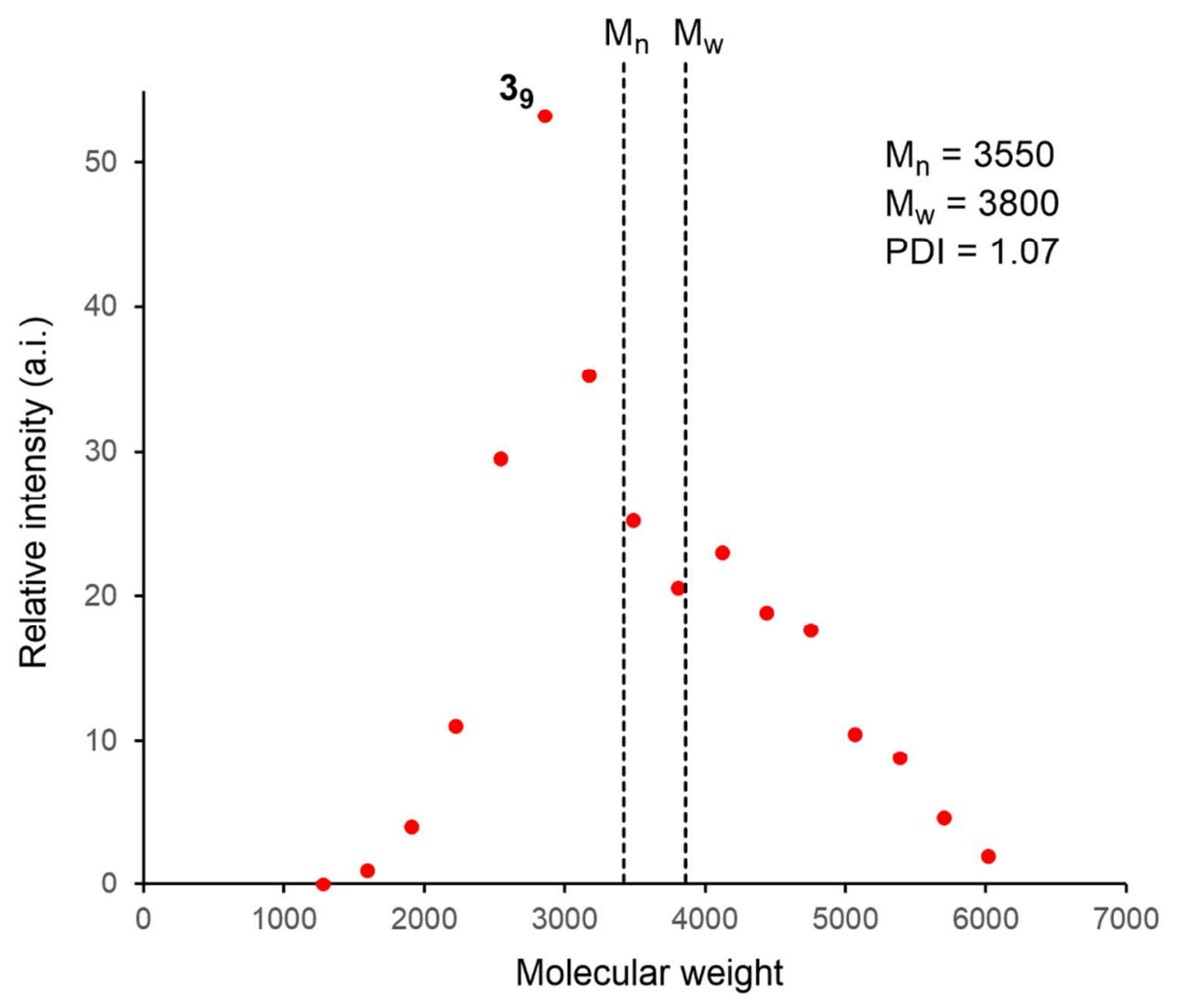

112

114 Figure 2. Oligomeric distribution generated by combining contributions from all of the $\mathbf{2}_{\boldsymbol{n}}$ series observed in Figure 1. 
116 A sample of the same oligomer was then oxidized with $\mathrm{H}_{2} \mathrm{O}_{2}$, converting all phosphines into phosphine

117 oxides. The affinity of the oxygen for $\mathrm{Ag}^{+}$is low, but is good for the harder $\mathrm{Na}^{+}$, so sodium ions were

118 used as the ionization aid in this analysis ${ }^{34}$. Overall, the signal was considerably weaker than for the

119 previous experiment, resulting in a noisier baseline (Figure 3).

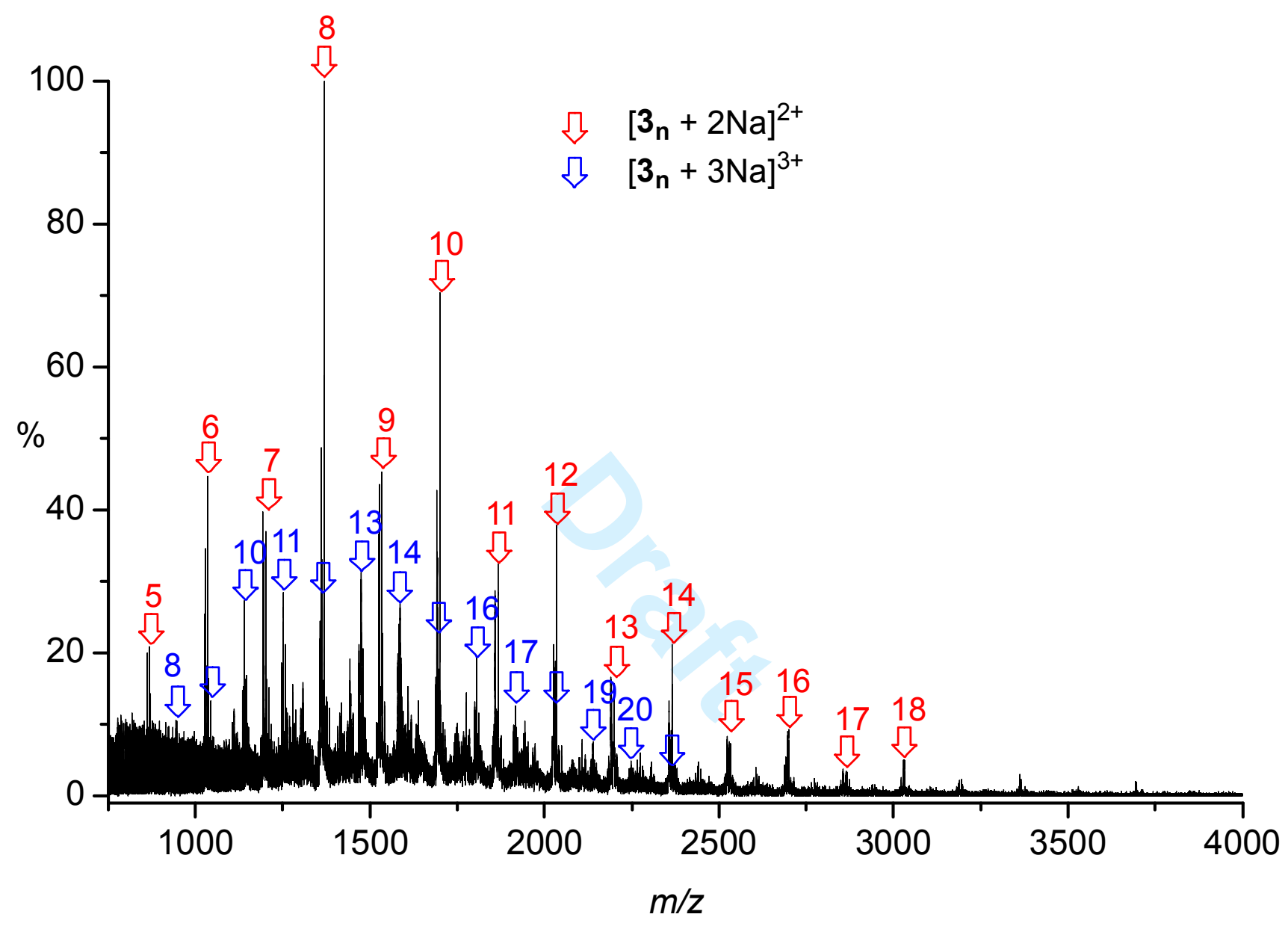

Figure 3. Positive ion ESI-MS of oligomerized and oxidized phosphaalkene 1 to make oligomeric mixture $\mathbf{3}_{\boldsymbol{n}}$, , recorded in acetonitrile with the addition of $\mathrm{NaI}$.

125 Just as in the unoxidized oligomeric mixture, no monocations were observed. There were two principal

126 series present, the most prominent series being the dications $\left[\mathbf{3 O}_{\mathbf{n}}+2 \mathrm{Na}\right]^{2+}$, which provided a

127 distribution between $n=5$ and $n=18$, with $n=8$ being most abundant. The dicationic nature of these 
128 species is given away by the peaks in the isotope pattern being $m / z 0.5$ apart. The next highest series

129 was $\left[\mathbf{3 O}_{\mathbf{n}}+3 \mathrm{Na}\right]^{3+}$, appearing between $n=8$ and $n=20$, and peaking at $n=13$ (all have peaks in the

130 isotope pattern $m / z 0.33$ apart). Some additional complexity appears because oxidation is not complete.

131 Thus, some peaks appear at intervals of $\mathrm{m} / \mathrm{z} 8(\mathrm{~m} / \mathrm{z} 5.33$ for the $3+$ species $)$ below the completely

132 oxidized oligomers.

133

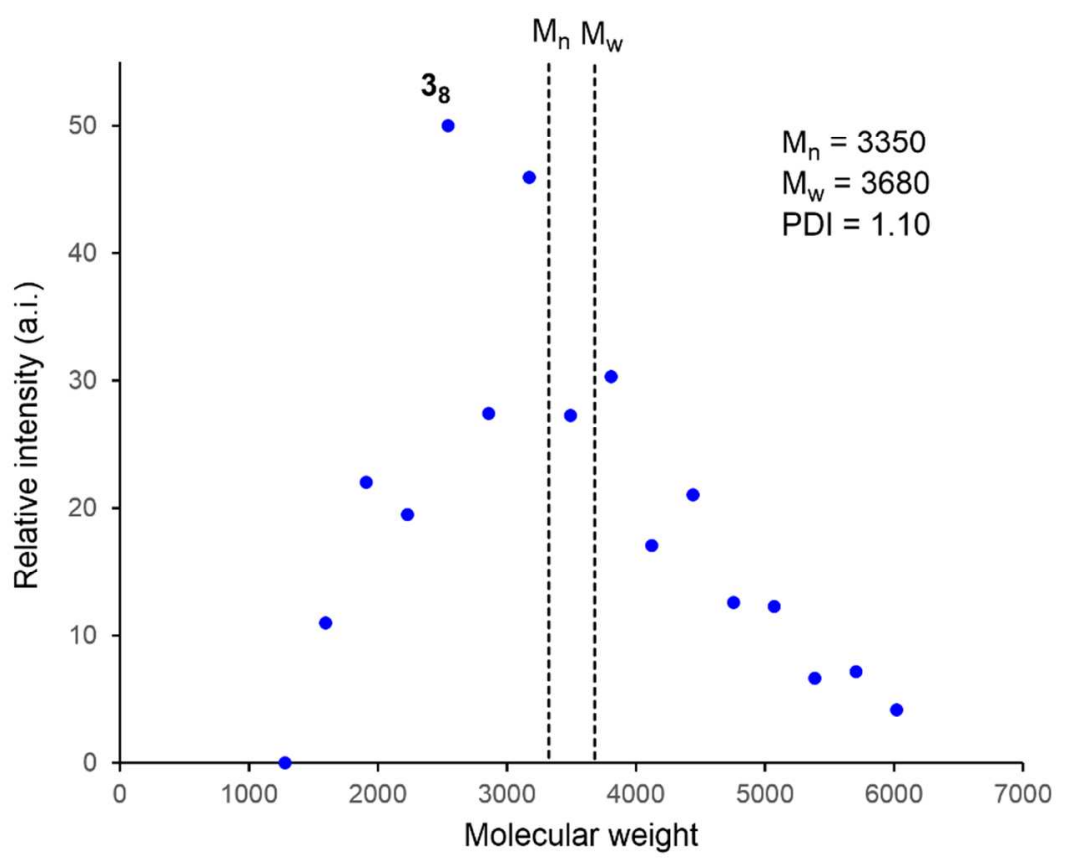

Figure 4. Oligomeric distribution generated by combining contributions from all of the $\mathbf{3}_{\boldsymbol{n}}$ series observed in Figure 3.

139 No oligomers below $n=4$ or above $n=20$ were observed, and the distribution maximises at $n=8$

140 (Figure 4). The $M_{n}$ and $M_{w}$ were calculated at 3350 and $3680 \mathrm{Da}$, respectively, giving a polydispersity

141 index of 1.10. This distribution was very similar to that observed for the unoxidized polymer, giving

142 confidence that the results are meaningful. $M_{n}$ values of $3450 \pm 100 \mathrm{Da}$ and a PDI of $1.09 \pm 0.01$ covers

143 both observed distributions, despite the fact the polymers are chemically distinct and the ionization 
144 mechanisms are quite different from one another. As such, we combined together both sets of results in

145 an averaged plot (Figure 5), which suggests the molecular weights of the oligomers form a pattern that

146 is quite close to a normal distribution. The fact that the estimated degree of polymerization $\left(\mathrm{DP}_{n} \approx 10\right)$

147 is larger than that expected for an oligomer generated from a [M]:[I] ratio of 4:1 (e.g. DP ${ }_{n}=4$ ) is not

148 unexpected since monomer 1 was not purified to the extent required for a "living" anionic

149 polymerization nor was the initiator (n-BuLi) titrated prior to use. For these reasons, the actual degree

150 of polymerization of $\mathbf{2}_{\mathbf{n}}$ or $\mathbf{3}_{\boldsymbol{n}}$ is expected to be higher than the calculated molecular weight from the

$151[\mathrm{M}]:[\mathrm{I}]$ ratio, as observed. Another possible explanation is that the higher molecular weight oligomers

152 have higher ionization efficiencies than the lower members of the series, regardless of the source of 153 ionization $\left(\mathrm{Ag}^{+}\right.$or $\left.\mathrm{Na}^{+}\right)$.

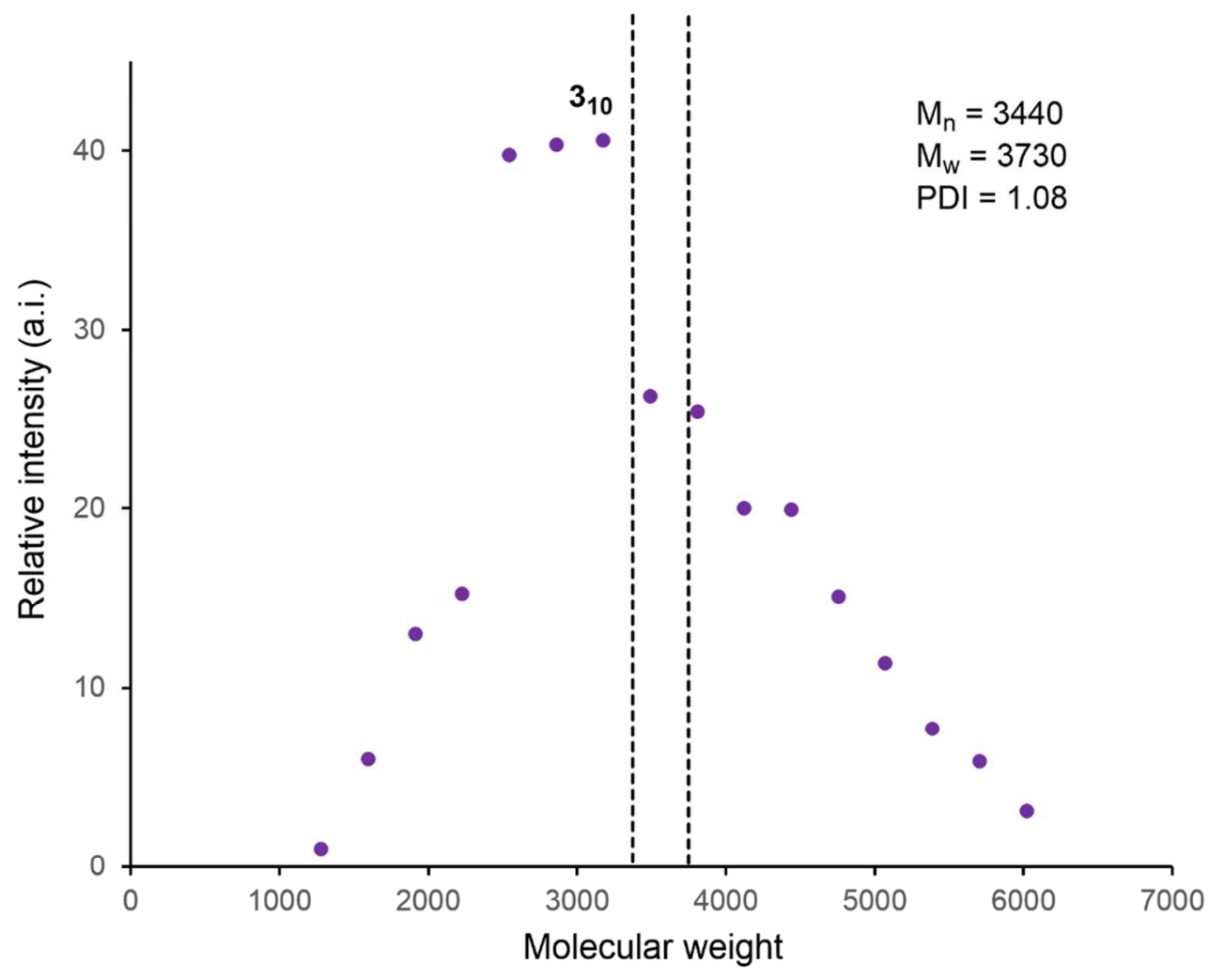

156 Figure 5. Oligomeric distribution generated by averaging the contributions from all of the $\mathbf{2}_{\boldsymbol{n}}$ series 
158 Failure to observe any oligomers of the form $\mathbf{4}_{n}$ suggests that the appearance of these species in the

159 MALDI-TOF MS of $\mathbf{3}_{\boldsymbol{n}}$ is a result of fragmentation. Although MALDI is generally a soft ionization

160 technique, it does of course involve intense laser ablation and this oligomer contains a high proportion

161 of aromatic rings that will absorb UV light effectively. Further evidence that fragmentation is

162 happening in MALDI can be gathered by examining the distribution of oligomers - it peaks at $\mathbf{3}_{3}$,

163 which by ESI does not exist in appreciable quantities at all in solution. It does seem that the

164 fragmentation observed is somewhat selective, as the fragments observed are primarily generated

165 through cleavage of a $\mathrm{P}-\mathrm{C}$ backbone bond (as opposed to the $\mathrm{P}-\mathrm{C}_{\text {mesityl }}, \mathrm{C}-\mathrm{C}, \mathrm{C}-\mathrm{H}$ or $\mathrm{P}=\mathrm{O}$ bonds).

166

167

\section{Experimental}

168

ESI-MS data were collected on a Waters Micromass Q-Tof micro mass spectrometer with Z-spray

electrospray source. Samples were infused from a $250 \mu \mathrm{L}$ gas-tight syringe at $10-40 \mu \mathrm{L} \mathrm{min}{ }^{-1}$ via

170

syringe pump. Instrument settings: capillary voltage $2900 \mathrm{~V}$, cone voltage $20 \mathrm{~V}$, source temperature $100{ }^{\circ} \mathrm{C}$, desolvation gas temperature $200^{\circ} \mathrm{C}$. Nitrogen was used as the desolvation gas.

172

173

174

175

176

177

178

179

180

181

182

\section{Conclusions}

ESI-MS appears to be an effective way of characterizing inorganic oligomers with phosphorus in the backbone. Addition of $\mathrm{Ag}^{+}$provided a suitable means of cationizing the phosphorus with available lone pairs, and $\mathrm{Na}^{+}$proved to have a strong affinity for phosphine oxides. Therefore, this approach should be generally useful to analyze oligomeric materials provided the choice of cation is judicious. One might expect, for example, that if the oligomers were transformed into phosphine sulfides that silver ions would be a better choice than sodium ions. The reverse would be true for a phosphazene oligomer. Like all such materials, as the average molecular weight of the polymeric compound rises the analysis 
183

184

185

186 187 188

will become more challenging; there will be more species with greater degrees of charging.

Furthermore, the overlap of signals increasingly become a problem and the ions will be distributed across many more values of $\mathrm{m} / \mathrm{z}$, hence degrading the signal-to-noise ratio. We plan to explore these limits in future work - how many repeat units can be added while still preserving reasonable data quality?

\section{Acknowledgements}

J.S.M. thanks the Natural Sciences and Engineering Research Council (NSERC) of Canada, the Canada Foundation for Innovation (CFI), the British Columbia Knowledge Development Fund (BCKDF), and the University of Victoria for instrumentation and operational funding.

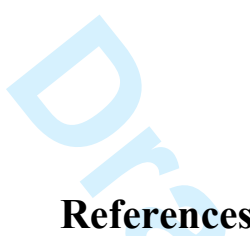

References

(1) Priegert, A. M.; Rawe, B. W.; Serin, S. C.; Gates, D. P. Chem. Soc. Rev. 2016, 45, 922.

(2) Caminade, A. M.; Majoral, J. P. New J. Chem. 2013, 37, 3358.

(3) Ren, Y.; Baumgartner, T. Dalton Trans. 2012, 41, 7792.

(4) Bates, J. I.; Dugal-Tessier, J.; Gates, D. P. Dalton Trans. 2010, 39, 3151.

(5) Baumgartner, T.; Réau, R. Chem. Rev. 2006, 106, 4681.

(6) Allcock, H. R. Dalton Trans. 2016, 45, 1856.

(7) Allcock, H. R. Chemistry and Applications of Polyphosphazenes, Wiley, Hoboken, 2003.

(8) For recent work, see: (a) Womble, C. T.; Coates, G. W.; Matyjaszewski, K.; Noonan, K. J. T. ACS Macro Lett. 2016, 5, 253. (b) Rawe, B. W.; Gates, D. P. Angew. Chem. Int. Ed. 2015, 54, 11438. (c) Marquardt, C.; Jurca, T.; Schwan, K. C.; Stauber, A.; Virovets, A. V.; Whittell, G. R.; Manners, I.; Scheer, M. Angew. Chem. Int. Edit. 2015, 54, 13782. (d) Schäfer, A.; Jurca, T.; Turner, J.; Vance, J. R.; Lee, K.; Du, V. A.; Haddow, M. F.; Whittell, G. R.; Manners, I.; Angew. Chem. Int. Ed. 2015, 54, 4836. (e) Guterman, R.; Kenaree, A. R.; Gilroy, J. B.; Gillies, E. R.; Ragogna, P. J. Chem. Mater. 2015, 27, 1412. (f) Wolf, T.; Steinbach, T.; Wurm, F. R. Macromolecules, 2016, 48, 3853. (g) Tian, Z. C.; Chen, C. Allcock, H. R. Macromolecules 2014, 47, 1065. (h) Matano, Y.; Ohkubo, H.; Honsho, Y.; Saito, A.; Seki, S.; Imahori, H. Org. Lett. 2013, 15, 932. (i) Wang, X.; Cao, K.; Liu, Y.; Tsang, B.; Liew, S. J. Am. Chem. Soc. 2013, 135, 3399. (j) He, X.; Woo, A. Y. Y.; Borau-Garcia, J.; Baumgartner, T. Chem. Eur. J. 2013, 19, 7620. (k) Greenberg, S.; Gibson, G. L.; Stephan, D. W. Chem. Commun. 2009, 304.

(9) Mark, J. E.; Allcock, H. R.; West, R., Inorganic Polymers. 2nd ed.; Oxford University Press: Oxford, 2005. 
218 (10) Pavelka, L. C.; Holder, S. J.; Baines, K. M. Chem. Commun. 2008, 2346.

219 (11) Pavelka, L. C.; Milnes, K. K.; Baines, K. M. Chem. Mater. 2008, 20, 5948.

220 (12) Tsang, C. W.; Yam, M.; Gates, D. P. J. Am. Chem. Soc. 2003, 125, 1480.

221 (13) Tsang, C. W.; Baharloo, B.; Riendl, D.; Yam, M.; Gates, D. P. Angew. Chem., Int. Ed. 2004, $22243,5682$.

223 (14) Noonan, K. J. T.; Gates, D. P. Angew. Chem., Int. Ed. 2006, 45, 7271.

224 (15) Noonan, K. J. T.; Patrick, B. O.; Gates, D. P. Chem. Commun. 2007, 3658.

225 (16) Noonan, K. J. T.; Feldscher, B.; Bates, J. I.; Kingsley, J. J.; Yam, M.; Gates, D. P. Dalton 226 Trans. 2008, 4451.

227 (17) Gillon, B. H.; Patrick, B. O.; Gates, D. P. Chem. Commun. 2008, 2161.

228 (18) Noonan, K. J. T.; Gillon, B. H.; Cappello, V.; Gates, D. P. J. Am. Chem. Soc. 2008, $130,12876$.

229 (19) Noonan, K. J. T.; Gates, D. P. Macromolecules 2008, 41, 1961.

230 (20) Dugal-Tessier, J.; Serin, S. C.; Castillo-Contreras, E. B.; Conrad, E. D.; Dake, G. R.; Gates, D. 231 P. Chem. Eur. J. 2012, 18, 6349.

232 (21) Rawe, B. W.; Chun, C. P.; Gates, D. P. Chem. Sci. 2014, 5, 4928.

233 (22) Priegert, A. M.; Siu, P. W.; Hu, T. Q.; Gates, D. P. Fire Mater. 2015, 39, 647.

234 (23) Serin, S. C.; Dake, G. R.; Gates, D. P. Dalton Trans. 2016, 45, 5659.

235 (24) Siu, P. W.; Serin, S. C.; Krummenacher, I.; Hey, T. W.; Gates, D. P. Angew. Chem., Int. Ed. $236 \mathbf{2 0 1 3}, 52,6967$.

237 (25) Gillon, B. H.; Gates, D. P. Chem. Commun. 2004, 1868.

238 (26) Blais, J.-C.; Turrin, C.-O.; Caminade, A.-M.; Majoral, J.-P. Anal. Chem. 2000, $72,5097$.

239 (27) Coessens, V.; Matyjaszewski, K. J. Macromol. Sci (A) 1999, 36, 653.

240 (28) Metters, O. J.; Chapman, A. M.; Robertson, A. P. M.; Woodall, C. H.; Gates, P. J.; Wass, D. F.; 241 Manners, I. Chem. Commun. 2014, 50, 12146.

242 (29) Fenn, J. B.; Mann, M.; Meng, C. K.; Wong, S. F.; Whitehouse, C. M. Mass Spectrom. Rev. 243 1990, 9, 37.

244 (30) Henderson, W.; McIndoe, J. S., Mass Spectrometry of Inorganic and Organometallic

245 Compounds: Tools - Techniques - Tips. John Wiley \& Sons: Chicester, 2005.

246 (31) Yunker, L. P. E.; Stoddard, R. L.; McIndoe, J. S. J. Mass Spectrom. 2014, 49, 1.

247 (32) Henderson, W.; Nicholson, B. K. J. Chem. Soc.-Chem. Commun. 1995, 2531.

248 (33) Öberg, E.; Orthaber, A.; Santoni, M.-P.; Howard, F.; Ott, S. Phosphorus, Sulfur, and Silicon 249 2013, $188,152$.

250 (34) Henderson, W.; McIndoe, J. S.; Nicholson, B. K.; Dyson, P. J. J. Chem. Soc., Dalton Trans. 251

252

253 1998, 519. 